УДК 342.9

DOI https://doi.org/10.17308/vsu.proc.law.2021.2/3389

\title{
СЛУЖЕБНОЕ ЗАКОНОДАТЕЛЬСТВО, РЕГУЛИРУЮЩЕЕ ОТНОШЕНИЯ ДИСЦИПЛИНАРНОЙ ОТВЕТСТВЕННОСТИ В СИСТЕМЕ ГОСУДАРСТВЕННОЙ СЛУЖБЫ: ПРОБЛЕМА ЭФФЕКТИВНОСТИ*
}

\author{
М. Б. Добробаба \\ Кубанский государственный университет \\ Поступила в редакцию 9 мая 2021 г.
}

\begin{abstract}
Аннотация: проводится анализ служебного законодательства, регулирующего отношения дисииплинарной ответственности в систеле государственной службы, на предмет его эбббективности. Автор делает вывод, что служебное законодательство, регулирующее исследуемьй правовой институт, не отвечает большинству паралетров его качества, что требует разработки адлинистративно-правовой модели правового регулирования отношений дисииплинарной ответственности государственных служащих, соответствующей их публичной правовой природе; определень направления совершенствования служебного законодательства, регулирующего исследуемый правовой институт.

Ключевые слова: служебное законодательство, эбббективность законодательства, качество законодательства, паралетры качества, государственная служба, государственнье служащие, эбббективность дисииплинарной ответственности, дисииплинарное производство, материальная ответственность.
\end{abstract}

\begin{abstract}
: the article analyzes the service legislation governing disciplinary responsibility in the civil service from the point of view of identifying the degree of its effectiveness. The author concludes that the service legislation governing the legal institution under study does not meet most of the parameters of its quality, which requires the development of an administrative-legal model of legal regulation of relations of disciplinary responsibility of civil servants, corresponding to its public legal nature; the directions of improving the service legislation governing the investigated legal institution were determined.

Key words: service legislation, effectiveness of legislation, quality of legislation, quality parameters, civil service, civil servants, the effectiveness of disciplinary responsibility, disciplinary proceedings, liability.
\end{abstract}

Проблема эффрективности служебного законодательства, регулирующего отношения дисциплинарной ответственности в системе государственной службы, актуальна и значима для разработки концептуальных

* Публикация подготовлена в рамках поддержанного РФФИ научного проекта № 20-011-00448 «Правовые механизмы обеспечения эффективности дисциплинарной ответственности в системе государственной службы: проблемы формирования».

(C) Добробаба М. Б., 2021 


\section{Вестник ВГУ. Серия: Право}

основ повышения эффективности данного вида юридической ответственности государственных служащих.

Термин «служебное законодательство» прочно вошел в юридическую терминологию в связи с формированием и развитием в нашей стране служебного права как подотрасли административного права ${ }^{1}$. Несмотря на неоднозначность понимания по содержанию и объему термина «законодательство» ${ }^{2}$, традиционно под служебным законодательством понимают совокупность всех федеральных нормативных актов и нормативных актов субъектов РФ, регулирующих отношения, связанные с государственной службой. Для подтверждения можно привести ст. 5 Федерального закона от 27 июля 2004 г. (в ред. от 24.03.2021) «О государственной гражданской службе Российской Федерации» ${ }^{3}$, в которой перечислены источники права, относящиеся к законодательству Российской Федерации о государственной гражданской службе.

Дисциплинарная ответственность государственных служащих представляет собой элемент их административно-правового статуса, что позволяет сделать вывод об административно-правовой природе данного вида юридической ответственности государственных служащих. Руководствуясь п. 4 ст. 10 Федерального закона от 27 мая 2003 г. № 58-ФЗ (в ред. от 23.05.2016) «О системе государственной службы Российской Федерации» ${ }^{4}$, источником правового регулирования дисциплинарной ответственности в системе государственно-служебных отношений являются федеральные законы о видах государственной службы. Однако до настоящего времени вопросы дисциплинарной ответственности регулируются и подзаконными актами, что вряд ли можно считать приемлемым, поскольку применение мер дисциплинарной ответственности ограничивает права и свободы государственного служащего, что допустимо только

фредеральным законом и в строго определенных случаях (ч. 3 ст. 55 Кон이 ституции РФ). Таким образом, постановка проблемы әфрфективности служебного законодательства, регулирующего отношения дисциплинарной ответственности, связана с анализом федеральных нормативных актов, регулирующих исследуемый правовой институт.

Для того чтобы выявить степень эфреективности служебного законодательства, регулирующего отношения дисциплинарной ответственности в системе государственной службы, следует определиться с содержанием категории «эфрфективность» применительно к служебному законодательству. Наиболее распространенной является так называемая целевая

${ }^{1}$ См., например: Старилов Ю. Н. Служебное право России : уже реальность или пока научная гипотеза? // Правовая наука и реформа юридического образования. 2013. № 3 (26). С. 99-116; Чаннов C. E. Вновь к вопросу о служебном праве // Государство и право. 2015. № 3. С. 5-11.

${ }^{2}$ См.: Иванов Р. Л. Понятие законодательства в современном российском праве // Вестник Омского ун-та. Серия «Право». 2013. № 3 (36). С. 6-16.

${ }^{3}$ Собр. законодательства Рос. Федерации. 2004. № 31. Ст. 3215.

${ }^{4}$ Там же. 2003. № 22. Ст. 2063. 
концепция эффрективности ${ }^{5}$, которой в настоящее время придерживается большинство ученых.

В научной литературе отсутствует единый подход к пониманию «эффрективности законодательства», что обусловлено тем, что категорию «эфрфективность законодательства» можно рассматривать в широком и узком понимании.

Так, в узкол понилании под «эфрфективностью служебного законодательства, регулирующего отношения дисциплинарной ответственности в системе государственной службы», следует понимать его результативность, т. е. соотношение между фрактическим результатом его действия и теми социальными целями, для достижения которых были приняты нормы, регулирующие дисциплинарную ответственность государственных служащих 6 . При таком подходе проводится количественная характеристика эбббективности .

Как известно, эфрфективным может быть признан только такой правовой институт, цели и задачи которого, обозначенные в законодательном акте, являются реализованными. Следует отметить, что применительно к специальной дисциплинарной ответственности в нормативных правовых актах отсутствует указание на ее цели, что свидетельствует о несовершенстве законодательства в этой области и приводит к активным попыткам восполнить законодательные пробелы на доктринальном уровне и в правоприменительной практике.

Представляется, что основная цель дисциплинарной ответственности государственных служащих заключается в превенции дисциплинарных проступков как в системе государственной службы в целом (общая превенция), так и конкретных государственных служащих (частная превенция). Ее достижение и определяет эфрфективность законодательства, регулирующего данный вид общественных отношений.

Соответственно, чем выше эффрективность служебного законодательства, тем качественнее работает предупредительный фрактор, снижая показатели служебной деликтности в системе государственной службы Российской Федерации. К сожалению, статистика совершения повторных дисциплинарных проступков в системе государственной службы не ведется, что делает возможным оценить эфрфективность служебного законодательства, регулирующего дисциплинарные отношения, только с позиции достижения цели общей превенции.

Как свидетельствует практика применения дисциплинарной ответственности, несмотря на наметившуюся незначительную тенденцию к

${ }^{5}$ См.: Добробаба М. Б. К вопросу об эфффективности дисциплинарной ответственности в системе государственной службы // Административное и муниципальное право. 2020. № 3. С. 13-26.

${ }^{6}$ См.: Эффрективность правовых норм / В. Н. Кудрявцев [и др.]. М., 1980. С. 22.

${ }^{7}$ См.: Пресняков М. В. Эфрфективность дисциплинарной ответственности на государственной гражданской службе : условия, фракторы и критерии // Современное право. 2020. № 11. С. 67-75. 


\section{Вестник ВГУ. Серия: Право}

снижению показателей привлечения государственных служащих к дисциплинарной ответственности, уровень служебной деликтности остается все еще очень высоким, что не позволяет сделать вывод о достижении цели общей превенции дисциплинарных проступков как в системе государственной службы.

Так, согласно статистическим данным за 2019 г., только в системе государственной гражданской службы к дисциплинарной ответственности было привлечено 27125 федеральных государственных гражданских служащих (что составило 4,9 \% от численности гражданских служащих) и 7129 государственных гражданских служащих субъектов РФ (3,3 \%). Для сравнения эти показатели в 2018 г. составляли 33957 человек в федеральных государственных органах $(5,1$ \%) и 8904 - в государственных органах субъектов РФ $(3,5 \%)^{8}$.

Если обратиться к статистике привлечения к дисциплинарной ответственности за коррупционные правонарушения, то в 2020 г. по инициативе органов прокуратуры при осуществлении надзора за соблюдением законодательства о противодействии коррупции к данному виду юридической ответственности было привлечено 73425 человек, что на 1,7 \% больше, чем за 2019 г., и в 23,5 раза превышает количество возбужденных дел за совершение коррупционных преступлений 9 .

В научной литературе обращается внимание, что объективно оценить эфрфективность законодательства можно лишь при соблюдении ряда условий $^{10}$, к которым применительно к служебному законодательству следует отнести:

- выполнение задач, для достижения которых принималась система норм, регулирующих институт дисциплинарной ответственности в служебном праве;

- относительно продолжительный период их действия;

- стабильность условий, в которых принимались и в настоящее время действуют нормы;

- репрезентативность исследования с точки зрения фредерального и регионального уровня государственного управления (федеральная государственная служба и государственная гражданская служба субъектов РФ); применительно к различным видам государственной службы (государственная гражданская служба, военная служба, государственная служба иных видов).

8 См.: Официальная статистическая информация Управления статистики труда Федеральной службы государственной статистики. URL: https://rosstat.gov. ru/folder/11110/document/13288 (дата обращения: 18.03.2021).

9 См.: Статистические сведения, опубликованные на официальном сайте Генеральной прокуратуры Российской Федерации. URL: https://epp.genproc. gov.ru/web/gprf/activity/statistics/office/result?item $=58866781$ (дата обращения: 18.03.2021).

${ }^{10}$ См.: Никулин С. И. Изучение эфрфективности законодательства - приоритетная научная задача современного отечественного правоведения // Вестник Рос. правовой акад. 2005. № 1. С. 74. 
В широкол слысле правовая категория «эфрфективность служебного законодательства, регулирующего отношения дисциплинарной ответственности в системе государственной службы», охватывает не только результативность, но и пробельность, избыточность служебного законодательства, наличие в нем коллизий и противоречий. Таким образом, речь идет не только о количественной, но и о качественной характеристике эфрфективности служебного законодательства.

Так, применяя широкий подход к изучению «эфрдективности законодательства», авторы определяют данную категорию как «способность оказывать оптимальное воздействие на соответствующие общественные отношения... ${ }^{11}$, «способность достигать при определенных условиях социально значимых целей» ${ }^{12}$. Примечательно, что в Толковом словаре Д. Н. Ушакова термин «способность» определяется как «состояние, качество, свойство, дающее возможность производить те или иные действия...» ${ }^{13}$. Исходя из этого, качество служебного законодательства - это его внутреннее свойство, детерминирующее возможность достижения эффективности. В свою очередь, категория «эфрдективность» соотносится с понятием «качество» как целое и часть, соответственно исследование эфффективности служебного законодательства обусловливается параметрами его качества.

В праве «качество законодательства» определяется как его способность удовлетворять потребности в правовом регулировании общественных отношений, входящих в предмет правового регулирования ${ }^{14}$. При этом к параметрам качества законодательства относят ${ }^{15}$ : параметры, связанные с определенностью норм; параметры стабильности законодательства; параметры, связанные с обеспечением свободы субъектов права и учетом интересов субъектов права и общества в целом; параметры учета системных связей в праве.

Названные параметры уточняются и детализируются в зависимости от специфики норм соответствующей отрасли (подотрасли) законодательства. При этом, как отмечает Ю. А. Тихомиров, рассуждая об эфреккивности закона, анализ результатов их реализации не должен ограничиваться сбором негативной информации. Оценке, наряду с показателями

${ }^{11}$ Тихонов Я. И. Эфрфективность уголовно-исполнительного законодательства и актов ФСИН России в свете юридической превенции // Уголовно-исполнительная система на современном этапе : взаимодействие науки и практики : материалы Междунар. науч.-практ. межведомственной конфр. (16-17 июня 2016 г.) / под общ. ред. А. А. Вотинова. Самара, 2016. С. 632.

${ }^{12}$ Мушинский M. А. Эфрфективность правотворческой деятельности и эффрективность законодательства : соотношение и критерии // Юрид. техника. 2012. № 6. C. 347-352.

13 Толковый словарь Д. Н. Ушакова. URL: https://dic.academic.ru/dic.nsf/ ushakov/1039266 (дата обращения: 19.03.2021).

${ }^{14}$ См.: Осипов М. Ю. Качество российского законодательства как ключ к повышению его эффрективности // Актуальные проблемы экономики и права. 2016. № 4. C. 92.

${ }^{15}$ См.: Там же. С. 92. 


\section{Вестник ВГУ. Серия: Право}

нарушений закона; информацией об отклонениях от норм закона ввиду их плохого качества, о пробелах в законодательстве, должны подлежать и другие правовые результаты, в том числе показатели позитивного использования закона для решения определенных задач; информация о благоприятных правовых последствиях ${ }^{16}$.

Преломляя названные параметры через специфику исследуемого правового института, на наш взгляд, оценить эфрфективность служебного законодательства, регулирующего отношения дисциплинарной ответственности в системе государственной службы, позволяют следующие параметры его качества:

1. Соответствие служебного законодательства правовой природе регулируемых общественных отношений.

Дисциплинарная ответственность является институтом служебного права - подотрасли административного права. Ее отличает от дисциплинарной ответственности работников круг лиц, на которых она распространяется; источники правового регулирования; более широкое понятие дисциплинарного проступка; целевое и фрункциональное предназначение; виды дисциплинарных взысканий и порядок их применения.

Как отмечает Ф. Н. Фаткуллин, на эффрективности нормы неизбежно сказывается правильный выбор общественных отношений, подлежащих правовому регулированию, и оптимальность выбора метода общего правового регулирования ${ }^{17}$. В связи с этим следует признать, что существующая модель дисциплинарной ответственности в системе государственной службы находится под сильным влиянием трудового права с присущей ему диспозитивностью.

Так, в действующем служебном законодательстве легализован подход, при котором решение вопроса о возбуждении дисциплинарного производства, даже при наличии для этого повода и фактического осно이 вания - предмет административного усмотрения субъекта дисциплинарной юрисдикции. По усмотрению субъекта дисциплинарной юрисдикции в большинстве случаев решается вопрос о проведении служебной проверки. Одновременно можно констатировать широту дискреционных полномочий представителя нанимателя, связанных с наложением дисциплинарных взысканий.

70 Полагаем, что подход законодателя, при котором процессуальный порядок привлечения государственных служащих к дисциплинарной ответственности недостаточно формализован, оставляет широкий простор административному усмотрению субъекта дисциплинарной юрисдикции, противоречит административно-правовой концепции построения служебного законодательства, предполагающей широкое применение метода императивного регулирования государственно-служебных отно-

${ }^{16}$ См.: Тихолиров Ю. А. Управление на основе права. М., 2007. С. 441-451.

${ }^{17}$ См.: Фаткуллин Ф. Н. Проблемы теории государства и права. Казань, 1987. C. 323 . 
шений, и негативно влияет на эфрдективность исследуемого правового института.

Требуется детальное законодательное оформление отдельных стадий внесудебного дисциплинарного производства, при этом следует рассмотреть вопрос о возможности расширения перечня субъектов дисциплинарной юрисдикции за счет создания системы коллегиальных органов (дисциплинарных комиссий). Представляется, в настоящее время существует острая потребность в разработке и принятии единого комплексного нормативного акта, направленного на регулирование государственно-служебных отношений, одним из разделов которого станет, при сохранении единства материальных и процессуальных норм, раздел, регулирующий дисциплинарную ответственность в системе государственной службы.

2. Полнота, конкретность, непротиворечивость норл служебного законодательства, регулируюших дисииплинарную ответственность.

Законодательство является эфрфективным только при условии безупречной сформулированности его норм, в том числе с точки зрения законодательной техники, когда их применение не вызывает затруднений в правоприменительной практике.

Однако анализ действующего служебного законодательства показывает, что оно не отличается полнотой и конкретностью правового регулирования, что требует своего решения:

- законодательно не регламентированы принципы дисциплинарной ответственности государственных служащих;

- отсутствует нормативно установленная классификация дисциплинарных проступков как по степени тяжести, так и по частоте совершения;

- не установлена связь между отнесением дисциплинарных проступков к той или иной категории и налагаемыми за их совершение дисциплинарными взысканиями, а также порядком их назначения;

- действующая система дисциплинарных взысканий, большинство из которых носит моральный характер либо является санкциями, лишающими возможности продолжать службу в данном органе, не всегда позволяет достичь цели дисциплинарной ответственности, что требует ее совершенствования за счет введения дополнительных мер дисциплинарного воздействия материального и статусного характера;

- законодательно не регламентированы правовые последствия дисциплинарной наказанности, связанные с ограничением применения мер поощрения применительно ко всем видам государственной службы, а также особенности снятия дисциплинарного взыскания в виде предупреждения о неполном должностном (служебном) соответствии;

- как мы уже отмечали, недостаточно регламентирован существующий порядок осуществления дисциплинарного производства, что обусловливает высокую степень административного усмотрения руководителя;

- нецелесообразным видится диффреренциация норм, регламентирующих дисциплинарную ответственность за совершение коррупционных 
правонарушений и норм, регулирующих обычную дисциплинарную ответственность государственных служащих;

- неоправданно существование отдельных видов дисциплинарных производств: общего внесудебного дисциплинарного производства и дисциплинарного производства по делам о коррупционных правонарушениях, которые, за исключением отдельных процедурных особенностей, практически идентичны и др.

3. Полнота законодательного регулирования правового статуса субъектов отношений дисииплинарной ответственности в систеле государственной службь.

К субъектам правоотношений дисциплинарной ответственности относятся три группы участников: субъекты дисциплинарной юрисдикции; субъекты, привлекаемые к дисциплинарной ответственности; иные участники отношений дисциплинарной ответственности, наделенные соответствующими полномочиями.

Если перечень полномочий субъектов дисциплинарной юрисдикции в служебном законодательстве имеет детальную правовую регламентацию, права и обязанности субъектов, совершивших дисциплинарные проступки, не имеют такого четкого нормативно-правового закрепления, что объясняется в научной литературе наличием возможности лиц, привлекаемых к дисциплинарной ответственности, осуществлять контроль за процедурами дисциплинарного производства, используя институт обжалования ${ }^{18}$.

Что касается иных субъектов правоотношений дисциплинарной ответственности, несмотря на то что в процессе осуществления служебной проверки используются показания свидетелей, привлекаются специалисты, переводчики, защитники, их процессуальный статус нормативно не закреплен.

Отсутствие детального нормативного регулирования процессуального статуса участников отношений дисциплинарной ответственности оказывает отрицательное воздействие на эффективность служебного законодательства. Представляется, что общие права и обязанности участников дисциплинарного производства следует закрепить в нормативных актах, регулирующих дисциплинарное производство применительно к отдельным видам государственной службы.

4. Способность обеспечить защиту прав и законньх интересов государственных служащих, являюшихся субъектали дисииплинарньх правоотношений.

Проводя анализ обозначенного параметра качества служебного законодательства, нет оснований утверждать, что правовое регулирование данного вопроса осуществляется с достаточной полнотой.

Защита прав и законных интересов государственных служащих осуществляется во внесудебном и судебном порядке. Если внесудебный по-

${ }^{18}$ См.: Махина С. Н. Субъекты дисциплинарного производства // Общее административное право : учебник / под ред. Ю. Н. Старилова. Воронеж, 2007. С. 658. 
рядок рассмотрения служебных споров комиссией государственного органа по служебным спорам после долгого отсутствия специальных норм, в связи с чем использовалось субсидиарное применение норм Трудового кодекса РФ, не так давно был регламентирован в служебном законодательстве ${ }^{19}$, то относительно судебного порядка рассмотрения судебных споров в судебной практике обнаруживается подход, при котором при их рассмотрении по аналогии применяются процессуальные нормы, регулирующие порядок рассмотрения трудовых споров.

На наш взгляд, существует необходимость в законодательной регламентации в виде отдельной главы Кодекса административного судопроизводства РФ $\Phi^{20}$ процессуальной фрормы рассмотрения служебных споров, связанных с проверкой законности и обоснованности наложенных на государственных служащих дисциплинарных взысканий при привлечении их к дисциплинарной ответственности.

Кроме того, публичный характер дисциплинарной ответственности также требует законодательного установления дополнительных гарантий лицам, ранее реализовавшим право на обжалование наложенных на них дисциплинарных взысканий в суд, в результате чего решение по дисциплинарному делу было пересмотрено. Представляется целесообразным закрепить, что в течение года после принятия данного решения применение мер дисциплинарной ответственности должно осуществляться только по итогам рассмотрения соответствующего вопроса комиссией по проведению служебной проверки, на заседание которой в обязательном порядке приглашается прокурор, осуществляющий надзор за соблюдением законодательства о государственной службе. В случае отсутствия прокурора на заседании комиссии материалы дисциплинарного дела, включая заключение комиссии по проведению служебной проверки, должны быть направлены прокурору для ознакомления.

Следует отметить, что служебному законодательству известно участие прокурора в дисциплинарном производстве в качестве субъекта, обеспечивающего защиту привлекаемого к дисциплинарной ответственности государственного служащего, сообщившего в правоохранительные или иные государственные органы или средства массовой информации о ставших ему известными фрактах коррупции (п. «а» ч. 21 Указа Президента от 2 апреля 2013 г. № $309^{21}$ ).

19 О внесении изменений в статью 70 Федерального закона «О государственной гражданской службе Российской Федерации» : фредер. закон от 20 июля 2020 г. № 227-ФЗ. URL: http://www.consultant.ru/document/cons_doc_ LAW_357787/\#dst100013

${ }^{20}$ Кодекс административного судопроизводства Российской Федерации : фердер. закон от 8 марта 2015 г. № 21-ФЗ (в ред. от 30.04.2021) // Собр. законодательства Рос. Федерации. 2015. № 10. Ст. 1391.

${ }^{21} \mathrm{O}$ мерах по реализации отдельных положений Федерального закона «О противодействии коррупции» : указ Президента РФ от 2 апреля 2013 г. № 309 (в ред. от 10.12.2020) // Собр. законодательства Рос. Федерации. 2013. № 14. Ст. 1470. 
5. Учет в служебном законодательстве системной связи между видами ответственности, применяельли в системе государственно-служебных отношений (дисииплинарной и материальной).

К сожалению, несмотря на то что материальная ответственность государственных служащих применяется за причинение материального ущерба публичному образованию - нанимателю в результате совершения дисциплинарных проступков, в служебном законодательстве четко не прослеживается взаимосвязь дисциплинарной и материальной ответственности государственных служащих.

В настоящее время только военнослужащие несут материальную ответственность на основании нормативного акта, имеющего административно-правовую природу (Федеральный закон от 12 июля 1999 г. № 161-ФЗ (в ред. от 08.06.2020) «О материальной ответственности военнослужащих») ${ }^{22}$. В силу отсутствия специального административно-правового акта на гражданских служащих и служащих федеральной государственной службы, связанной с правоохранительной деятельностью, распространяются нормы трудового законодательства, регулирующие материальную ответственность работников.

Материальная ответственность государственных служащих неразрывно связана с дисциплинарной ответственностью, поскольку обязанность беречь государственное имущество, в том числе имущество, которое предоставлено для исполнения должностных обязанностей, имеет публично-правовой характер для всех видов государственных служащих, а не только для военнослужащих. Не случайно при проведении служебной проверки наряду с другими обстоятельствами устанавливается характер и размер вреда, причиненного служащим в результате дисциплинарного проступка ${ }^{23}$.

ح Принимая во внимание особую публичную правовую природу материальной ответственности государственных служащих, представляется необходимость в разработке и нормативном регулировании ее административно-правовых основ, что позволит отнести материальную ответственность государственных служащих всех видов (а не только военнослужащих) к институту служебного права ${ }^{24}$.

Таким образом, в настоящее время нет оснований для вывода о высоком качестве служебного законодательства, регулирующего отношения дисциплинарной ответственности в системе государственной службы, что, в свою очередь, не позволяет добиться его эффективности. Причина этого видится в несоответствии избранной законодателем модели правового регулирования дисциплинарной ответственности государственных

${ }^{22}$ Собр. законодательства Рос. Федерации. 1999. № 29. Ст. 3682.

${ }^{23}$ См., например: Пункт 4 ч. 2 ст. 59 Федерального закона «О государственной гражданской службе Российской Федерации».

${ }^{24}$ См.: Добробаба М. Б. Дисциплинарная ответственность в системе государственно-служебных правоотношений : дис. ... д-ра юрид. наук. Саратов, 2017. C. 47 . 
служащих ее публичной правовой природе, что требует изменения подхода законодателя в регулировании исследуемого института исключительно нормами административного права.

Направлением систематизации служебного законодательства должна стать разработка и принятие единого комплексного нормативного акта, направленного на регулирование государственной службы, одним из разделов которого станет раздел, регулирующий дисциплинарную ответственность в системе государственно-служебных отношений.

Вместе с тем только лишь высокого качества служебного законодательства недостаточно для обеспечения эфрфективности дисциплинарной ответственности в служебном праве. Как справедливо указывается в научной литературе, к фракторам эфрфективности законодательства, наряду с качеством правовых норм, относится также деятельность по их применению ${ }^{25}$.

Представляется, что направлениями совершенствования служебного законодательства, регулирующего отношения дисциплинарной ответственности в системе государственной службы, должны стать:

1) нормативное закрепление целей и принципов дисциплинарной ответственности государственных служащих;

2) переход к административно-правовой модели его построения;

3) детальная правовая регламентация материального аспекта дисциплинарной ответственности государственных служащих и процессуального механизма ее реализации;

4) унификация норм, регулирующих материальные и процессуальные аспекты привлечения государственных служащих к обычной дисциплинарной ответственности и ответственности за совершение дисциплинарных коррупционных проступков как важного направления систематизации законодательства в данной сфрере;

5) осуществление административно-правовой регламентации материальной ответственности государственных служащих всех видов государственной службы с отражением системной связи дисциплинарной и материальной ответственности в служебном праве;

6) разработка и принятие единого комплексного нормативного акта, направленного на регулирование государственной службы, одним из разделов которого станет раздел, регулирующий дисциплинарную ответственность в системе государственной службы.

\section{Библиографический список}

Глазырин В. В., Никитинский В. И. Эффективность правоприменительных актов // Советское государство и право. 1984. № 2. С. 11-17.

Добробаба M. Б. Дисциплинарная ответственность в системе государственно-служебных правоотношений : дис. ... д-ра юрид. наук. Саратов, 2017. $463 \mathrm{c}$.

${ }^{25}$ См.: Глазырин В. В., Никитинский В. И. Эфрфективность правоприменительных актов // Советское государство и право. 1984. № 2. С. 11. 
Добробаба М. Б. К вопросу об эффективности дисциплинарной ответственности в системе государственной службы // Административное и муниципальное право. 2020. № 3. С. 13-26.

Иванов Р. Л. Понятие законодательства в современном российском праве // Вестник Омского ун-та. Серия «Право». 2013. № 3 (36). С. 6-16.

Мушинский М. А. Эффективность правотворческой деятельности и әффективность законодательства : соотношение и критерии // Юрид. техника. 2012. № 6. C. 347-352.

Никулин С. И. Изучение әффективности законодательства - приоритетная научная задача современного отечественного правоведения // Вестник Российской правовой академии. 2005. № 1. С. 73-75.

Общее административное право : учебник / под ред. Ю. Н. Старилова. Воронеж : Изд-во Воронеж. гос. ун-та, 2007.

Осипов М. Ю. Качество российского законодательства как ключ к повышению его эффективности // Актуальные проблемы экономики и права. 2016. № 4. C. 88-95.

Пресняков М. В. Эффективность дисциплинарной ответственности на государственной гражданской службе : условия, фракторы и критерии // Современное право. 2020. № 11. С. 67-75.

Старилов Ю. Н. Служебное право России : уже реальность или пока научная гипотеза? // Правовая наука и реформа юридического образования. 2013. № 3 (26). C. 99-116.

Тихомиров Ю. А. Управление на основе права. М. : Формула права, 2007. $485 \mathrm{c}$.

Тихонов Я. И. Эфффективность уголовно-исполнительного законодательства и актов ФСИН России в свете юридической превенции // Уголовно-исполнительная система на современном этапе : взаимодействие науки и практики : материалы Междунар. науч.-практ. межведомственной конф. (16-17 июня 2016 г.) / под общ. ред. А. А. Вотинова. Самара : Самарский юрид. ин-т ФСИН России, 2016. С. 632-634.

Толковый словарь Д. Н. Ушакова. URL: https://dic.academic.ru/dic.nsf/ ushakov/1039266

Фаткуллин Ф. Н. Проблемы теории государства и права : курс лекций. Казань : Изд-во Казан. ун-та, 1987. 334 с.

Чаннов C. $E$. Вновь к вопросу о служебном праве // Государство и право. 76 2015. № 3. C. 5-11.

Эффрективность правовых норм / В. Н. Кудрявцев [и др.]. М. : Юрид. лит., 1980. $280 \mathrm{c}$.

\section{References}

Glazyrin V. V., Nikitinsky V. I. The effectiveness of law enforcement acts // Soviet state and law. 1984. No. 2. P. 11-17.

Dobrobaba M. B. Disciplinary responsibility in the system of state-official legal relations: dis. ... Dr. jurid. sciences. Saratov, 2017. 463 p.

Dobrobaba M. B. On the issue of the effectiveness of disciplinary responsibility in the system of public service // Administrative and municipal law. 2020. No. 3. P. $13-26$. 
Ivanov R. L. The concept of legislation in modern Russian law // Bulletin of Omsk University. Series "Right". 2013. No. 3 (36). P. 6-16.

Mushinsky $M$. A. The effectiveness of lawmaking and the effectiveness of legislation: ratio and criteria // Legal technology. 2012. No. 6. P. 347-352.

Nikulin S. I. Studying the effectiveness of legislation is a priority scientific task of modern domestic jurisprudence // Bulletin of the Russian Legal Academy. 2005. No. 1. P. 73-75.

General administrative law: textbook / ed. Yu.N. Starilova. Voronezh: Voronezh State University Publishing House, 2007.

Osipov $M$. Yu. The quality of Russian legislation as a key to increasing its efficiency // Actual problems of economics and law. 2016. No. 4. P. 88-95.

Presnyakov $M$. $V$. The effectiveness of disciplinary responsibility in the civil service: conditions, factors and criteria // Modern Law. 2020. No. 11. P. 67-75.

Starilov Yu. N. Service law of Russia: is it already a reality or is it still a scientific hypothesis? // Legal science and reform of legal education. 2013. No. 3 (26). P. 99-116.

Tikhomirov Yu. A. Law-based management. M.: Formula Prava, 2007. 485 p.

Tikhonov Ya. I. The effectiveness of criminal executive legislation and acts of the Federal Penitentiary Service of Russia in the light of legal prevention // Criminal executive system at the present stage: interaction of science and practice: materials of the International Scientific and Practical Interdepartmental Conference (June 16-17, 2016) / edited by A. A. Votinova. Samara: Samara Law Institute of the Federal Penitentiary Service of Russia, 2016. P. 632-634.

Explanatory dictionary of D. N. Ushakov. URL: https://dic.academic.ru/dic. nsf/ushakov/1039266

Fatkullin F. N. Problems of the theory of state and law: a course of lectures. Kazan: Kazan University Publishing House, 1987. 334 p.

Channov S. E. Again to the issue of service law // State and Law. 2015. No. 3. P. 5-11.

The effectiveness of legal norms / V. N. Kudryavtsev [et al.]. M. : Jurid. lit., 1980. 280 p.

Кубанский государственный универcumem

Добробаба М. Б., доктор юридических наук, доцент, профбессор кафбедры административного и фбинансового права

E-mail: dobrobaba_mb@mail.ru
Kuban State University

Dobrobaba M. B., Doctor of Legal Sciences, Associate Professor, Professor of the Administrative and Financial Law Department

E-mail:dobrobaba_mb@mail.ru 